\title{
The allylic oxidation of unsaturated steroids by tert-butyl hydroperoxide using homogeneous and heterogeneous cobalt acetate $\uparrow$
}

\author{
Jorge A. R. Salvador and James H. Clark \\ Clean Technology Centre, Chemistry Department, University of York, York, UK YO10 5DD
}

\begin{abstract}
Received (in Liverpool, UK) 8th September 2000, Accepted 14th November 2000
First published as an Advance Article on the web 11th December 2000
\end{abstract}

Cobalt acetate is an effective catalyst for the selective allylic oxidation of unsaturated steroids using tert-butyl hydroperoxide especially when used in a supported form when it can be easily recovered and reused.

Allylic oxidation is a reaction of fundamental importance in organic chemistry with applications in areas ranging from agricultural products to pharmaceuticals. ${ }^{1,2}$

The allylic oxidation of unsaturated steroids such as $\Delta^{5}$ steroids has traditionally been carried out with chromium reagents such as $\mathrm{CrO}_{3}$-pyridine complex, ${ }^{3}$ chromium trioxide and 3,5-dimethylpyrazole, ${ }^{4}$ pyridinium chlorochromate, (PCC), ${ }^{5,6}$ pyridinium dichromate (PDC), ${ }^{6}$ sodium chromate, ${ }^{7}$ sodium dichromate in acetic acid ${ }^{8}$ and pyridinium fluorochromate. ${ }^{9}$ However the large excess of reagent used in these procedures along with a difficult work-up and production of environmentally hazardous chromium residues, makes these reactions increasingly unacceptable on a commercial scale. Of greater preparative interest has been the use of hydroperoxides combined with different types of catalysts. ${ }^{10-17}$ Despite the good yields reported with $\mathrm{CrO}_{3},{ }^{10}$ hexacarbonylchromium $\mathrm{Cr}(\mathrm{CO})_{6},{ }^{11,12}$ pyridinium dichromate ${ }^{13}$ and $\mathrm{RuCl}_{3}{ }^{14}$ to prepare allylic oxidation products from $\Delta^{5}$-steroids, the toxicity of the chromium compounds and the high cost of the ruthenium catalyst renders the procedures unsuitable for commercialisation and led us to recently report the use of cuprous salts, $\mathrm{CuBr}$, $\mathrm{CuCl}, \mathrm{Cul}$, and a cupric salt $\mathrm{CuCl}_{2}$, as well as copper metal as catalysts for this type of reaction. ${ }^{17}$

Allylic oxidation of steroids, particularly at the 7-position, has attracted interest over many years. The $\Delta^{5}$-steroids can be oxidised to 5-en-7-ones, which are known as inhibitors of sterol biosynthesis and have some use in cancer chemotherapy. ${ }^{18}$ This has encouraged us to find new, more environmentally acceptable methods for this reaction. The heterogenisation of inorganic reagents and catalysts useful in organic reactions is a very important area in clean technology. ${ }^{19}$ In this communication we report the use of cobalt acetate in homogeneous, $\left(\mathrm{Co}(\mathrm{OAc})_{2} \cdot 4 \mathrm{H}_{2} \mathrm{O}\right)$, and more importantly, heterogeneous forms (catalysts $\mathbf{1}, \mathbf{2}$, and $\mathbf{3}$ prepared as reported previously ${ }^{20,21}$ ) for this type of allylic oxidation reaction.

Using $\Delta^{5}$-steroids 4-7 and $\mathbf{1 2}$ as substrates (Scheme 1) allylic oxidation products 8-11 and $\mathbf{1 3}$ were obtained in very high, isolated yields, $70-86 \%$ (Table 1). Apart from the reaction with substrate $\mathbf{6}$ which required benzene as solvent and a temperature of $70{ }^{\circ} \mathrm{C}$ all the reactions were performed in acetonitrile using a milder temperature of $50-55^{\circ} \mathrm{C}$. The best results were obtained using the supported catalyst $\mathbf{3}$ which may be a result of its greater organophilic character. No significant reaction occurs in the absence of catalyst or in the presence of the catalyst support only.

In a typical reaction to a solution of 17 -oxoandrost-5-en-3 $\beta$ yl acetate $4(660.90 \mathrm{mg} 2 \mathrm{mmol})$ in acetonitrile $(12 \mathrm{ml})$ under nitrogen, catalyst $3\left(60 \mathrm{mg}\right.$, cobalt loading $\left.0.41 \mathrm{mmol} \mathrm{g}^{-1}\right)$ and tert-butyl hydroperoxide (ca. $2.4 \mathrm{ml} 12 \mathrm{mmol}$ ) were added. After $24 \mathrm{~h}$ under magnetic stirring at $50{ }^{\circ} \mathrm{C}$, the catalyst was removed by filtration and the solution was poured into sodium sulphite solution (10\% aq.) and extracted with diethyl ether. The

$\dagger$ UK Patent applied for

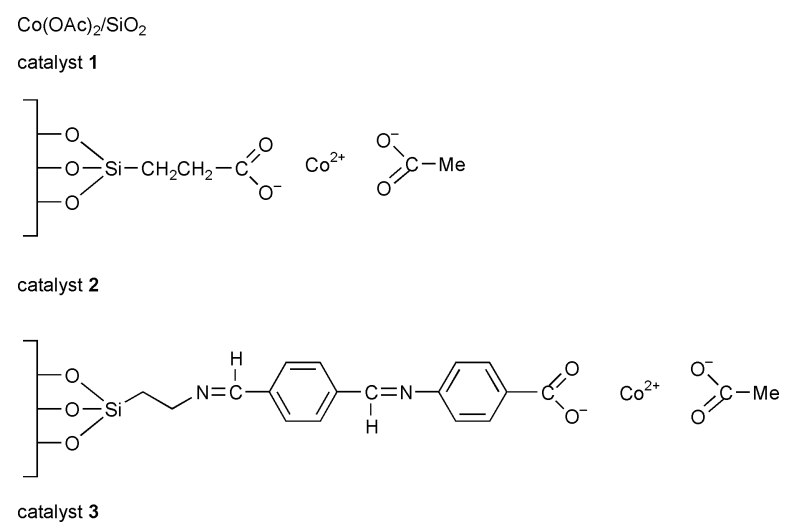

extract was washed with aq. saturated solution of $\mathrm{NaHCO}_{3}$, water, dried and evaporated to dryness to give 7,17-dioxoandrost-5-en-3 $\beta$-yl acetate. These reactions are very selective compared to those carried out using $\mathrm{Fe}(\mathrm{acac})_{3}$ as catalyst reported by Kimura et al. ${ }^{15,16} \mathrm{Mo}(\mathrm{CO})_{6}$ has also been described as catalyst for this reaction, but this led to epoxidation of the cholesteryl acetate under similar oxidative conditions. ${ }^{16}$

While the product yields of the allylic oxidations are very similar under homogeneous and heterogeneous conditions, the easier recovery of the catalyst in the heterogeneous reactions make these more environmentally friendly processes. Furthermore using the heterogeneous catalysts $\mathbf{2}$ and $\mathbf{3}$ it was possible to reuse the catalyst with only a small reduction in the product yields, under similar experimental conditions ( $80 \%$ for recycled catalyst 2 and $81 \%$ for recycled catalyst 3 , Table 1). Our catalytic method is also effective for other unsaturated steroids. Thus the $\Delta^{4}$-steroid $\mathbf{1 4}$ gives the testosterone acetate 15, in a yield of $70 \%$ (Scheme 2). Furthermore, the method is also effective in the presence of an oxidatively vulnerable secondary alcohol group. The steroid $\mathbf{1 6}$ is oxidised to the alcohol product 17 with impressive selectivity (71\%) (Scheme 2).

In summary we have discovered a new efficient and relatively environmentally friendly method for the preparation<smiles>C[C@H]1CC[C@]2(C)C(=CCC3C2CC[C@]2(C)C3CC[C@@H]2O)C1</smiles>
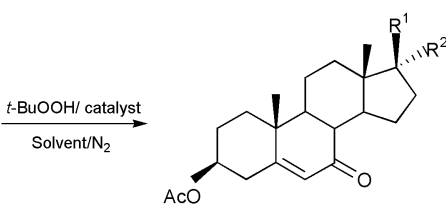

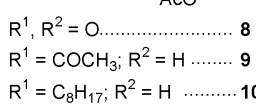

$\ldots R^{1}=H ; R^{2}=H \ldots \ldots \ldots \ldots \ldots \ldots$

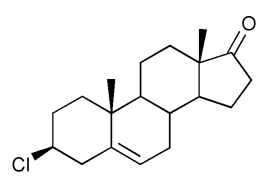

12

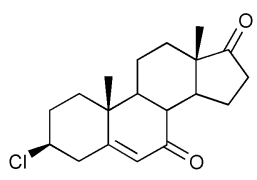


Table 1 Allylic oxidation of unsaturated steroids

\begin{tabular}{|c|c|c|c|c|c|c|c|}
\hline $\begin{array}{l}\text { Substrate/ } \\
\text { mmol }\end{array}$ & $t-\mathrm{BuOOH}^{a} / \mathrm{ml}$ & Catalyst/mmol Co & Solvent & Time/h & Temp.$/{ }^{\circ} \mathrm{C}$ & Prod. & $\begin{array}{l}\text { Isolated } \\
\text { yield }(\%)\end{array}$ \\
\hline $4 / 1$ & 1.2 & $\mathrm{Co}(\mathrm{OAc})_{2} \cdot 4 \mathrm{H}_{2} \mathrm{O} / 0.012$ & $\mathrm{CH}_{3} \mathrm{CN}$ & 20 & 50 & 8 & $84^{b}$ \\
\hline $5 / 2$ & 2.4 & $\mathrm{Co}(\mathrm{OAc})_{2} \cdot 4 \mathrm{H}_{2} \mathrm{O} / 0.024$ & $\mathrm{CH}_{3} \mathrm{CN}$ & 24 & 50 & 9 & 86 \\
\hline $4 / 1$ & 1.2 & $1 / 0.01$ & $\mathrm{CH}_{3} \mathrm{CN}$ & 18 & 50 & 8 & 85 \\
\hline $4 / 1$ & 1.2 & $2 / 0.009$ & $\mathrm{CH}_{3} \mathrm{CN}$ & 20 & 50 & 8 & 84 \\
\hline $4 / 1$ & 1.2 & 2/(recycled, 0.008$)$ & $\mathrm{CH}_{3} \mathrm{CN}$ & 20 & 50 & 8 & 80 \\
\hline $4 / 1$ & 1.2 & $1 / 0.005$ & $\mathrm{CH}_{3} \mathrm{CN}$ & 24 & 50 & 8 & $40^{c}$ \\
\hline $6 / 1$ & 1.2 & $2 / 0.022$ & Benzene & 48 & 70 & 10 & $70^{c}$ \\
\hline $4 / 1$ & 1.2 & $3 / 0.016$ & $\mathrm{CH}_{3} \mathrm{CN}$ & 20 & 55 & 8 & 85 \\
\hline $4 / 1$ & 1.2 & 3/ (recycled, 0.014) & $\mathrm{CH}_{3} \mathrm{CN}$ & 20 & 55 & 8 & $81^{b}$ \\
\hline $4 / 2$ & 2.4 & $3 / 0.0025$ & $\mathrm{CH}_{3} \mathrm{CN}$ & 24 & 55 & 8 & 86 \\
\hline $5 / 2$ & 2.4 & $3 / 0.0025$ & $\mathrm{CH}_{3} \mathrm{CN}$ & 20 & 50 & 9 & $82^{b}$ \\
\hline $7 / 1$ & 1.2 & 3/ 0.007 & $\mathrm{CH}_{3} \mathrm{CN}$ & 24 & 55 & 11 & $72^{c}$ \\
\hline $12 / 0.65$ & 0.8 & $3 / 0.016$ & $\mathrm{CH}_{3} \mathrm{CN}$ & 20 & 55 & 13 & $73^{c}$ \\
\hline $14 / 0.63$ & 0.8 & $\mathbf{3} / 0.006$ & $\mathrm{CH}_{3} \mathrm{CN}$ & 3 & 55 & 15 & $70^{c}$ \\
\hline $16 / 1$ & 1.2 & $3 / 0.016$ & $\mathrm{CH}_{3} \mathrm{CN}$ & 24 & 55 & 17 & $71^{d}$ \\
\hline
\end{tabular}

a 5.0-6.0 M solution in decane (Aldrich). ${ }^{b}$ Traces of starting material and a by-product are visible by TLC but not detectable in the ${ }^{1} \mathrm{H}-\mathrm{NMR}$ spectra $(500$ $\mathrm{MHz}$ ) of the crude product. ${ }^{c}$ Recovered by flash chromatography (ethyl acetate-petroleum ether $40-60{ }^{\circ} \mathrm{C}$ ). ${ }^{d} \mathrm{Calculated}$ on the basis of the ${ }^{1} \mathrm{H}-\mathrm{NMR}$ signal $(6 \mathrm{H})$ of the crude product.
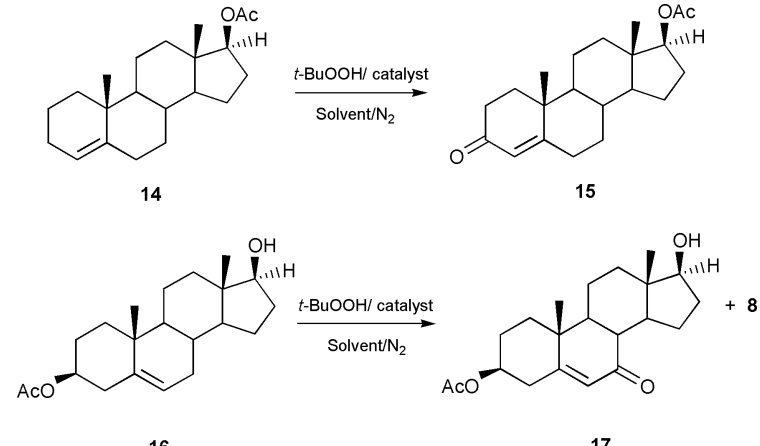

16

17

Scheme 2

of $\Delta^{5}$-7-oxo-steroid and $\Delta^{4}$-3-oxo-steroid from easily available steroid substrates using $t$ - $\mathrm{BuOOH}$ as the oxidant and supported $\mathrm{Co}$ (II) as an easily recoverable and reusable catalyst. A study of the effects of different oxidants and other types of heterogeneous catalyst on this and related reactions is presently under investigation.

We wish to thank the RAEng-EPSRC for a Clean Technology Fellowship (to J. H. C.) and the Universidade de Coimbra for financial support (to J. A. R. S.).

\section{Notes and references}

1 J. Muzart, Bull. Soc. Chim. Fr., 1986, 65, 2.

2 P. C. Bulman Page and T. J. Mccarthy, in Comprehensive Organic Synthesis, ed. B. M. Trost and I. Flemming, 1 Pergamon Press, Oxford, New York, Seoul, Tokyo, 1991, vol. 7, p. 83.
3 G. W. Dauben, M. Lorber and D. S. Fullerton, J. Org. Chem., 1969, 34, 3587; D. S. Fullerton and C. M. Chen, Synth. Commun., 1976, 6, 217.

4 W. G. Salmond, M. A. Barta and J. L. Havens, J. Org. Chem., 1978, 43, 2057.

5 E. J. Parish, S. Chitrakorn and T.-Y. Wei, Synth. Commun., 1986, 16, 1371.

6 E. J. Parish and T.-Y. Wei, Synth. Commun., 1987, 17, 1227.

7 C. W. Marshall, R. E. Ray, I. Laos and B. Reigel, J. Am. Chem. Soc., 1957, 79, 6308.

8 A. Amann, G. Ourisson and B. Luu, Synthesis, 1987, 1002.

9 E. J. Parish, H. Sun and S. A. Kizito, J. Chem. Res., 1996, 544

10 J. Muzart, Tetrahedron. Lett., 1987, 28, 4665.

11 A. J. Pearson, Y. S. Chen, Y. S. Hsu and T. Ray, Tetrahedron Lett., 1984, 25, 1235.

12 A. J. Pearson, Y. S. Chen, G. R. Hang, S. Y. Hsu and T. Ray, J. Chem. Soc., Perkin Trans. 1, 1985, 267.

13 N. Chidambaram and S. Chandrasekaran, J. Org. Chem., 1987, 52, 5048.

14 R. A. Miller, W. Li and G. R. Humprey, Tetrahedron Lett., 1996, 37, 3429.

15 M. Kimura and T. Muto, Chem. Pharm. Bull., 1979, 27, 109.

16 M. Kimura and T. Muto, Chem. Phar. Bull., 1980, 28, 1836.

17 J. A. R. Salvador, M. L. Sá e Melo and A. S. Campos Neves, Tetrahedron Lett., 1997, 38, 119.

18 Y. Sato, Y. Sonoda, M. Morisaki and N. Ikekawa, Chem. Pharm. Bull., 1984, 32, 3305; K. P. Cheng, H. Nagana, L. Bang and G. Ourisson, J. Chem. Res. (S), 1997, 217; H. Nagana, J. P. Poyser, K. P. Cheng, L. Bang and G. Ourisson, J. Chem. Res. (S), 1997, 218; V. Kumar, A. Alain, G. Ourisson and B. Luu, Synth. Commun., 1987, 17, 1279.

19 J. H. Clark, Catalysis of Organic Reactions using Supported Inorganic Reagents, VCH, New York, 1994; Chemistry of Waste Minimisation, ed. J. H. Clark, Chapman and Hall, London, 1995.

20 A. J. Butterworth, J. H. Clark, P. H. Walton and S. J. Barlow, Chem. Commun., 1996, 1859.

21 J. Chisem, I. C. Chisem, J. S. Rafelt, D. J. Macquarrie and J. H. Clark, Chem. Commun., 1997, 2203. 